\title{
Época de colheita e capacidade germinativa de sementes de Tibouchina mutabilis (Vell.) Cogn. (Melastomataceae)
}

\author{
Edson Simão ${ }^{1}$, Adriana Tiemi Nakamura ${ }^{1}$ \& Massanori Takaki ${ }^{2,3}$
}

Biota Neotropica v7 (n1) - http://www.biotaneotropica.org.br/v7n1/pt/abstract?article +bn01507012007

\author{
Recebido em 01/09/06 \\ Versão reformulada recebida em 27/11/06 \\ Publicado em 31/01/2007
}

\author{
'Programa de pós-graduação em Ciências Biológicas, Biologia Vegetal, \\ Instituto de Biociências, UNESP, Rio Claro \\ e-mail: simão@rc.unesp.br, tiemi@ibb.unesp.br \\ ${ }^{2}$ Departamento de Botânica, Instituto de Biociências, CP 199, UNESP, \\ Bela Vista, CEP 13506-900, Rio Claro, SP, Brasil \\ ${ }^{3}$ Autor para correspondência: Massanori Takaki,e-mail: massa@rc.unesp.br
}

\begin{abstract}
Simão, E., Nakamura, A.T. \& Takaki, M. Harvest period and germination capacity of Tibouchina mutabilis (Vell.) Cogn. (Melastomataceae) seeds. Biota Neotrop. Jan/Apr 2007 vol. 7, no. 1 http://www.biotaneotropica.org.br/v7n1/pt/abstract?article+bn01507012007 ISSN 1676-0603.

An important step for understanding the dynamic of plant species in their environment is the study of their reproductive feature. Tibouchina mutabilis (Vell.) Cogn. (Melastomataceae) is a characteristic species of Serra do Mar, with potential for recovery of degraded areas and with landscaping purpose. The aim of this study was to investigate the acquisition of germination capacity of seeds and establishment of the best period for fruit harvest by weekly harvests, when morphological and germination capacity features were observed in four stages of development. The T. mutabilis seeds germinated only under white light. Besides the necessity of light for germination, seeds of T. mutabilis did not show another type of dormancy at the end of the ripening, with high germination percentage. The germination rate increases progressively in the function of lose of moisture in the subsequent stages of development, suggesting that the high moisture was the factor that restricted the germination. The best indicator of physiological maturation of seeds is the natural opening of the capsule. The advantage of this parameter is that it can be widely utilized and it is easy to recognize it. Due to the anemochoric dispersion of seeds, we propose that the harvest must be done, with good results, of fruit with 21 days after anthesis, and drying the fruit for capsule opening for seed extraction.
\end{abstract}

Keywords: seed germination, seed maturation, morphology.

\section{Resumo}

Simão, E., Nakamura, A.T. \& Takaki, M. Época de colheita e capacidade germinativa de sementes de Tibouchina mutabilis (Vell.) Cogn. (Melastomataceae). Biota Neotrop. Jan/Apr 2007 vol. 7, no. 1 http://www.biotaneotropica.org.br/v7n1/pt/abstract?article+bn01507012007 ISSN 1676-0603.

O estudo dos aspectos reprodutivos é um importante passo para entendermos a dinâmica das espécies em seu ambiente natural. Tibouchina mutabilis (Vell.) Cogn. (Melastomataceae), espécie característica da Serra do Mar, apresenta potencial para recuperação de áreas degradadas e para fins paisagísticos. Objetivou-se investigar a aquisição da capacidade germinativa das sementes e o estabelecimento da melhor época para colheita de frutos da espécie por meio de coletas semanais, onde as características morfológicas e a capacidade germinativa foram observadas, em quatro estádios de desenvolvimento. A capacidade germinativa foi observada com 14 dias pósantese e a máxima germinação foi observada aos 21 dias. As sementes T. mutabilis germinaram somente na luz. Além da necessidade da luz para a germinação, as mesmas não apresentaram nenhum tipo de dormência na fase final de maturação, apresentando alta porcentagem de germinação, A velocidade de germinação aumentou progressivamente em função do dessecamento das sementes nas subseqüentes fases avaliadas, sugerindo que a alta umidade foi o fator limitante para a germinação. O melhor indicador de maturação fisiológica e de fácil observação, para a espécie, é o início da abertura natural das cápsulas, entretanto, devido às sementes anemocóricas pequenas, propomos que as colheitas dos frutos sejam realizadas 21 dias pós-antese e antes da abertura das cápsulas, neste caso, as sementes devem ser mantidas dentro do fruto para secagem, em condição ambiente.

Palavras-chave: fisiologia, germinação, maturação, morfologia, Tibouchina. 


\section{Introdução}

Um dos grandes problemas enfrentados por viveiristas e tecnólogos de sementes está relacionado à época ideal da colheita de sementes de espécies florestais. Surgem aí perguntas sem resposta definida, como: qual o ponto de maturidade do fruto compatível com maturidade da semente? Isto tem relação com a dormência? É difícil fazer afirmações a respeito destas informações pelos diversos fatores ambientais envolvidos, como luz, temperatura, variabilidade genética e peculiaridades de cada espécie.

Determinações físicas e bioquímicas de frutos e sementes podem indicar a maturidade ideal e quando devem ser colhidos os frutos visando à obtenção de maiores percentuais de germinação (Pereira \& Mantovani 2001). Durante a maturação fisiológica, as modificações da morfologia do fruto são visíveis e podem ser vistas até a maturidade, podendo estar associada ou não à deiscência ou abscisão dos mesmos.

Após atingirem o ponto de maturidade fisiológica, as sementes tendem a desligar-se da planta (Carvalho \& Nakagawa 1980). Este ponto é obtido quando as sementes atingem o máximo de poder germinativo e vigor (Popinigis 1985). Existem determinações adicionais, tais como peso, densidade, matéria seca, tamanho e teor de umidade, que indicam esta maturidade (Carvalho \& Nakagawa 1980).

As determinações mais utilizadas têm sido o teor de umidade e o peso da matéria seca, comprovados com sementes de Bixa orellana (Amaral et al. 1999), Tibouchina granulosa (Lopes et al. 2005), Mucuna aterrima (Nakagawa et al. 2005) e Trigonella coerulea (Akhalkatsi \& Lösch 2005). A coloração e o aspecto morfológico dos frutos são medidas práticas de avaliação (Amaral et al. 1999), porém não tão precisas.

Durante o processo de maturação ocorrem modificações bioquímicas, morfológicas e fisiológicas, iniciadas com a fecundação do óvulo e cessam quando as sementes atingem sua máxima qualidade fisiológica (Pereira \& Mantovani 2001), apresentando o máximo de poder germinativo e vigor (Popinigis 1985).

Deste modo, estudos que visam ao entendimento do processo reprodutivo das espécies tornam-se necessários, principalmente na questão de produção de sementes e mudas para reabilitação de áreas degradadas. Determinações de padrões definidos de aspectos morfológicos, fisiológicos e melhor época para colheita dos frutos são fundamentais e de grande auxílio para viveiristas e tecnólogos de sementes.

Para o presente estudo, selecionou-se Tibouchina mutabilis, espécie pioneira, característica da encosta úmida da Serra do Mar, que e ocorre do Rio de Janeiro até Santa Catarina na floresta pluvial da encosta Atlântica. É encontrada quase exclusivamente na mata secundária, chegando, por vezes, a constituir-se na espécie dominante (Lorenzi 1992). Tabarelli \& Mantovani (1999) destacam a grande representatividade da família Melastomataceae no banco de sementes em Floresta Atlântica Montana com muitos indivíduos, incluindo Tibouchina mutabilis. Apesar da ocorrência de sementes de espécies do gênero Tibouchina no banco de sementes, Barroso et al. (1999) destacam que as espécies de Melastomataceae apresentam grande número de sementes abortadas.

Além da importância ecológica, T. mutabilis é muito utilizada em arborização urbana, com fins paisagísticos, devido à beleza de suas flores e pequeno porte, sendo também utilizadas na recuperação de áreas degradadas e reflorestamento (Lorenzi 1992, Backes \& Irgang 2004).

O objetivo deste estudo foi investigar a aquisição da capacidade germinativa e caracterizar a melhor época para a colheita de frutos de Tibouchina mutabilis (Vell.) Cogn. que resultem em sementes de boa qualidade e vigor, observando as características anatômicas e a capacidade de germinação em diferentes estádios de maturação.

\section{Material e Métodos}

O presente estudo foi conduzido no Laboratório de Fotomorfogênese de Plantas do Departamento de Botânica, Unesp, Rio Claro, SP. O acompanhamento do desenvolvimento das sementes de Tibouchina mutabilis foi realizado pós-antese, mediante a marcação das flores. Foram marcadas 100 flores na antese (flores de cor branca) distribuídas em três árvores de jardins da cidade Rio Claro. As marcações foram feitas em agosto, com placas de alumínio numeradas presas ao pedúnculo da flor. Para a determinação dos estádios de desenvolvimento das sementes, foram realizadas colheitas semanais pós-antese (7, 14, 21 e 28 dias). Em cada colheita, foram retirados 15 frutos sendo 5 em cada árvore. Dessas amostras, 5 frutos foram retirados aleatoriamente, para extração de sementes. Parte das sementes foi fixada em FAA 50 (Johansen 1940) e conservada em álcool etílico $70 \%$. As demais sementes que apresentavam o embrião formado ou em desenvolvimento foram utilizadas nos testes de germinação.

Para o estudo anatômico, as sementes foram desidratadas e incluídas em historresina Leica, segundo protocolo do fabricante, seccionadas em micrótomo rotativo, com $8 \mu \mathrm{m}$ de espessura. As seções obtidas foram coradas com ácido periódico - reativo de Schiff (PAS) e azul de toluidina (Feder \& O`Brien 1968), sendo montadas com Entellan. O material foi ilustrado por meio de fotomicrografias obtidas em fotomicroscópio Olympus, modelo PM-20. Para todas as ilustrações, foram preparadas escalas nas condições ópticas adequadas.

Os 10 frutos restantes foram distribuídos individualmente em potes de vidro e mantidos em temperatura ambiente até a sua abertura natural. As sementes liberadas foram peneiradas (peneira com malha de $0,35 \mathrm{~cm}$ de diâmetro) eliminando as impurezas e as sementes morfologicamente mal formadas. Um estudo piloto indicou que as sementes que passaram por esta malha não germinam, e a observação deste material em lupa comprovou que nestas sementes não há o desenvolvimento do embrião.

As sementes foram embebidas em água destilada por 24 horas, na presença de luz, contadas e destas retiradas as sementes que apresentavam embrião visível. O procedimento foi realizado para os dez frutos e no final, as sementes foram homogeneizadas em um único lote, sendo colocadas para germinar.

Para os testes de germinação, quatro placas de Petri $(5 \mathrm{~cm}$ de diâmetro) foram forradas com duas folhas de papel filtro umedecidas com água destilada, com 25 sementes por placa. As placas foram acondicionadas em caixas do tipo "gerbox", transparente ou preta, conforme o tratamento (luz e escuro), posteriormente mantidas em estufas incubadoras para B.O.D. ou germinadores com temperatura ajustável, com luz branca de lâmpadas fluorescentes a $32,85 \mu \mathrm{mol} \cdot \mathrm{m}^{-2} \cdot \mathrm{s}^{-1}$ ao nível da semente.

O monitoramento dos experimentos foi diário (até 70 dias) e sementes com raiz com pelo menos $1 \mathrm{~mm}$ de comprimento foram consideradas germinadas. As sementes germinadas foram contadas e removidas das placas. Para os tratamentos controle no escuro, as contagens de sementes germinadas foram feitas sob luz verde de segurança (Amaral-Baroli \& Takaki 2001).

Os dados obtidos foram utilizados para o cálculo da germinabilidade (G), tempo médio (T), velocidade média (VM) e o índice de sincronização (U) da germinação (Labouriau \& Agudo 1987).

Os resultados foram analisados estatisticamente através de Análise de Variância (ANOVA) e teste de comparação de médias de Tukey, ambos em nível de significância $\alpha=0,05$ (Sokal \& Rohlf 1981). Os dados foram transformados em arco seno $\sqrt{p / 100}$ antes das análises. 


\section{Resultados}

Os estádios de desenvolvimento e maturação das sementes de Tibouchina mutabilis foram divididos em quatro fases pós-antese: 7, 14,21 e 28 dias. A tabela 1 representa as três primeiras fases. O estádio de 28 dias não foi representado pois a abertura natural das cápsulas liberou parte das sementes, inviabilizando a contagem. O número de sementes com embrião desenvolvido ou em desenvolvimento foi crescente nos diferentes estádios avaliados (Tabela 1).

A espécie estudada apresentou sementes com embrião desenvolvido em aproximadamente $10 \%$ das sementes e com capacidade para germinar quando secas com apenas 14 dias pós-antese (Tabela 1). Nesta fase a porcentagem de germinação foi baixa, com cerca de $14 \%$ (Figura $1 \mathrm{~B}$ ).

As respostas de germinação (Figura 1) nos diferentes estádios de desenvolvimento foram distintas e a germinação só ocorreu na presença da luz. Em sementes frescas, a germinação não ocorreu nos estádios de 7 e 14 dias. No estádio de 7 dias, o embrião está no início do seu desenvolvimento (Figura 2 A,B) enquanto que no estádio de 14 dias o embrião de algumas sementes está parcialmente desenvolvido (Figura 2 C,D). Nos estádios de 21 e 28 dias, as mesmas apresentaram embrião desenvolvido, preenchendo toda a amêndoa (Figura 2e, f, g).
As porcentagens de germinação foram significativamente maiores nos estádios de 21 e 28 dias ( 87 e $83 \%$ respectivamente) sem diferença estatisticamente significativas entre ambos $(\mathrm{p}<0,05$ de acordo com o teste de Tukey).

Para o estádio de 28 dias das sementes frescas, o teste de germinação não foi realizado, pois considerou-se que este lote de sementes já estava seco, devido a abertura natural das cápsulas e dispersão de sementes. Portanto, as respostas de germinação nesta fase representam as sementes frescas e secas (Figura 1).

Assim como a porcentagem de germinação, a velocidade e o índice de sincronização da germinação também apresentaram respostas distintas nos diferentes estádios de desenvolvimento (Figura 1 C,D e Figura 3). Nos tratamentos com sementes frescas, a velocidade de germinação foi baixa, aumentando progressivamente em função do tempo de colheita, sendo a mais alta observada no estádio de 28 dias pós-antese (Figura 1C). A velocidade de germinação foi maior em sementes secas, 21 e 28 dias pós-antese (Figura 1 D), e a exemplo da porcentagem de germinação, não houve diferença significativa entre ambos.

Nas sementes de 21 dias, frescas ou secas, não ocorreu diferença significativa para índice de sincronização, mas como mostra o gráfico de freqüência relativa (Figura 3 b, c), a distribuição da germinação foi distinta entre os tratamentos. Para sementes frescas, a germinação

Tabela 1. Número de sementes por fruto (sementes desenvolvidas) em diferentes estádios de maturação para T. mutabilis.

Table 1. Number of seeds per fruit (developed seeds) in different stages of maturation to T. mutabilis.

\begin{tabular}{ccccc}
\hline $\begin{array}{c}\text { Estádio de } \\
\text { maturação }\end{array}$ & $\mathbf{1 0}$ frutos amostrados & $\mathbf{N}^{\mathbf{0}}$ de sementes total & $\begin{array}{c}\mathbf{N}^{\mathbf{0}} \text { de sementes } \\
\text { com embrião }\end{array}$ & $\begin{array}{c}\text { Sementes com } \\
\text { embrião visível (\%) }\end{array}$ \\
\hline $1^{\mathbf{0}}$ semana & Total & 4.681 & 0,0 & 0,0 \\
& Média & 468,1 & 0,0 & 0,0 \\
& D.P.* & 181,4 & 0,0 & 0,0 \\
\hline $2^{\mathbf{0}}$ semana & Total & 5.079 & 476 & 9,4 \\
& Média & 507,9 & 47,6 & 10,2 \\
& D.P. & 182,1 & 32,9 & 7,6 \\
\hline $3^{\mathbf{0}}$ semana & Total & 5.355 & 843 & 15,7 \\
& Média & 535,5 & 84,3 & 15,3 \\
& D.P.* & 137,2 & 54,2 & 7,9 \\
\hline
\end{tabular}

* Desvio Padrão da média

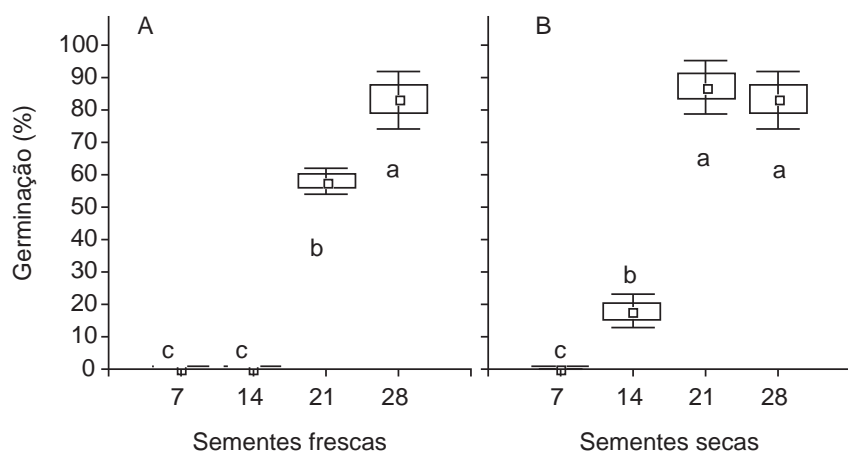

Dias após a antese

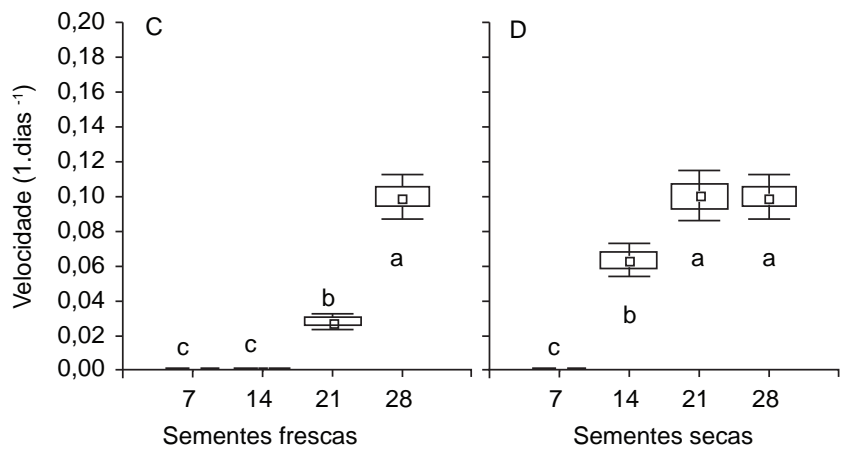

Dias após a antese

Figura 1. Germinação de sementes de T. mutabilis nos diferentes estádios de maturação, testadas sob luz branca contínua. A) sementes frescas; B) sementes secas; C) velocidade de germinação para sementes frescas; e D) sementes secas. Letras distintas indicam diferença significativa entre si $\mathrm{p}<0,05$ de acordo com o teste d e Tukey.

Figure 1. T. mutabilis seed germination in different stages of ripening, evaluated under continuous white light. A) fresh seeds; B) dry seeds; C) germination rate to fresh seeds; and D) germination rate to dry seeds. Distinct words indicate significantive difference among treatment $\mathrm{p}<0.05$ of according to Tukey test. 

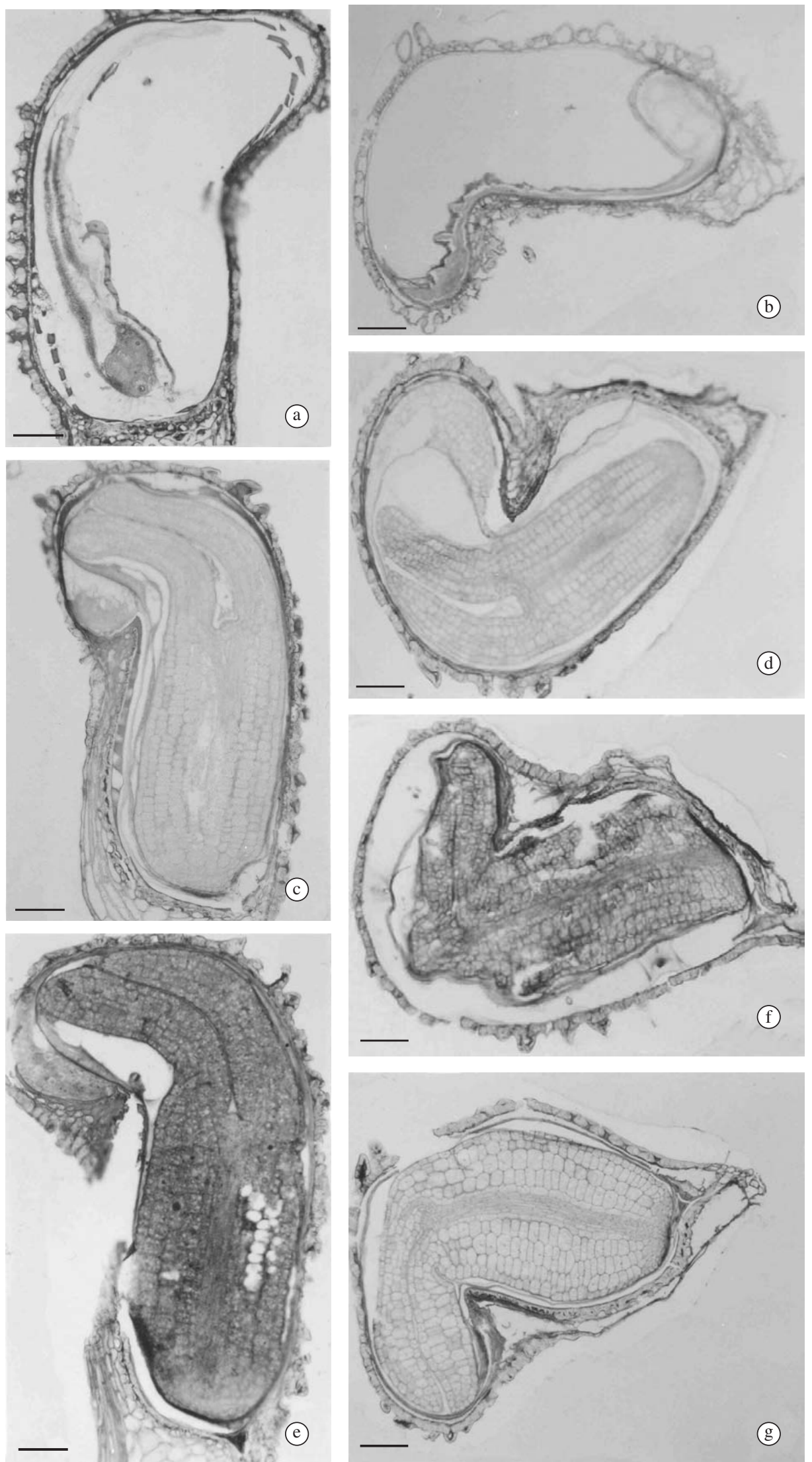

Figura 2. Secções longitudinais da semente de T. mutabilis. a) 7 dias-fresco; b) 7 dias-seco; c) 14 dias-fresco; d) 14 dias-seco; e) 21 dias-fresco; f) 21 diasseco; e g) 28 dias. Barras de escala: $80 \mu \mathrm{m}$.

Figure 2. Longitudinal section of T. mutabilis seeds. a) 7 days-fresh; b) 7 days-dry; c) 14 days-fresh; d) 14 days-dry; e) 21 days-fresh; f) 21 days-fresh; and g) 28 days. Scale bars: $80 \mu \mathrm{m}$. 
ocorreu em picos ao longo do tempo. Nas sementes secas o tempo de germinação foi menor e a distribuição da mesma ocorreu de forma acumulada, com a maioria germinando do $7^{\circ}$ ao $15^{\circ}$ dias seguindo eventos isolados de germinação. $\mathrm{O}$ lote de 14 dias sementes secas apresentou o menor valor de índice de sincronização, indicando assim maior sincronização da germinação neste estádio (Figura 1a), embora a porcentagem final de geminação tenha sido baixa (Figura 1b).

Aos 21 dias pós-antese, as sementes de T. mutabilis apresentaram embriões formados e capazes de germinar em altas porcentagens. As cápsulas ainda estão fechadas, mas o embrião já está morfologicamente desenvolvido (Figura 2 e, f), sendo comprovado com os testes de germinação após o dessecamento, indicando a maturidade fisiológica e morfológica, uma vez que a porcentagem de germinação neste estádio (87\%) foi semelhante ao estádio correspondente à dispersão (83\%).

\section{Discussão}

A floração e a frutificação na espécie estudada foram irregulares, com frutos em diferentes estádios de desenvolvimento nas árvores
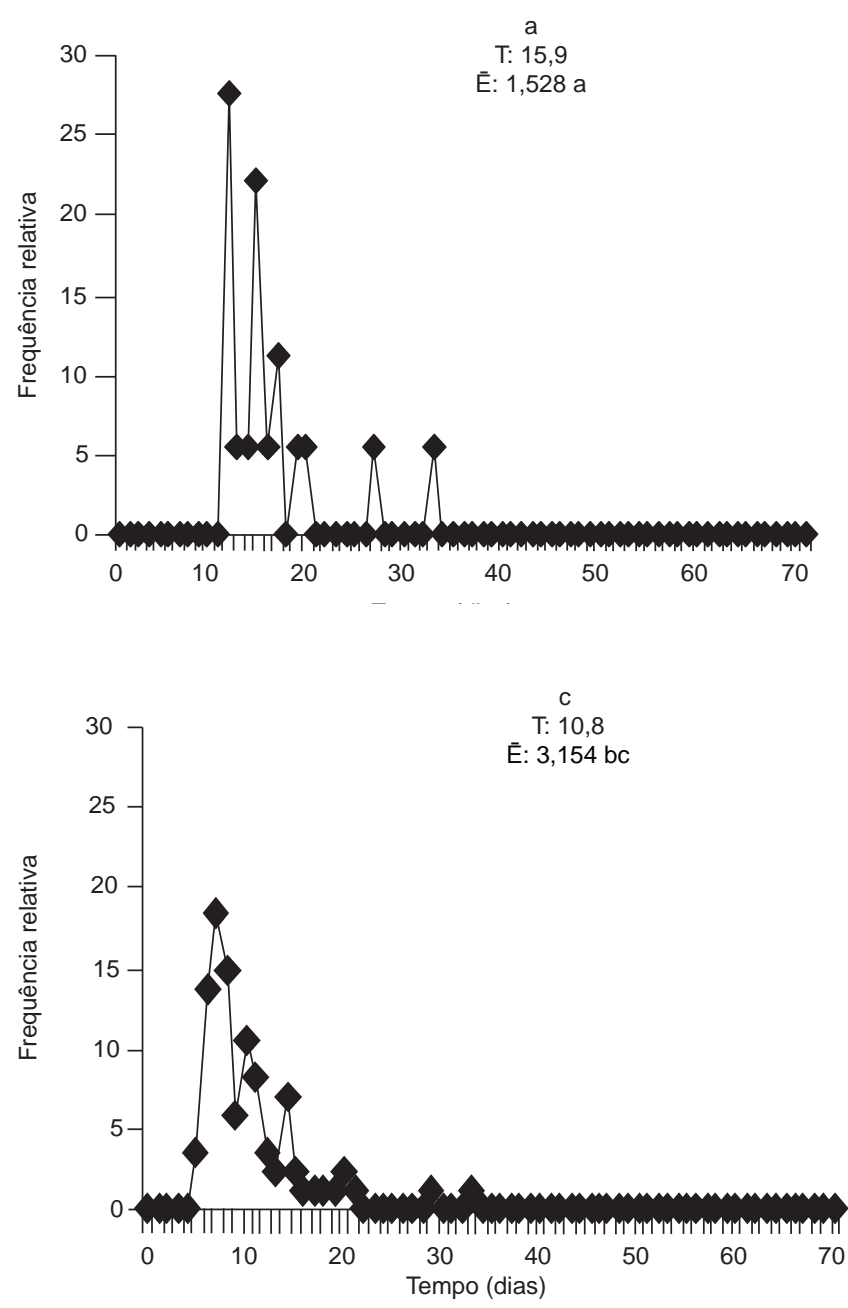

amostradas. Essas características também foram observadas em outra espécie de Melastomataceae, Miconia cinnamomifolia (Pereira \& Mantovani 2001). As sementes de T. mutabilis também apresentaram desenvolvimento irregular em um mesmo fruto.

Esta característica pode estar relacionada à disponibilidade de recursos para a planta ou mesmo à falta de fertilização de todos os óvulos presentes no fruto, explicando, pelo menos em parte, a ocorrência de um grande número de sementes abortadas encontradas na espécie estudada e em outras espécies de Melastomataceae (Zaia \& Takaki 1998, Barroso et al. 1999).

A disponibilidade de recursos pode influenciar na floração, produção de sementes e germinação de algumas espécies, como observado por Akhalkatsi \& Lösch (2005) em Trigonella coerulea, cultivada sob ambiente com limitado recurso hídrico.

Os frutos são drenos que competem com órgãos vegetativos por nutrientes, água e outros compostos. Da mesma forma, os fitormônios produzidos pelos frutos e sementes para o seu desenvolvimento, poderiam ter ação inibitória ao crescimento e ao desenvolvimento de
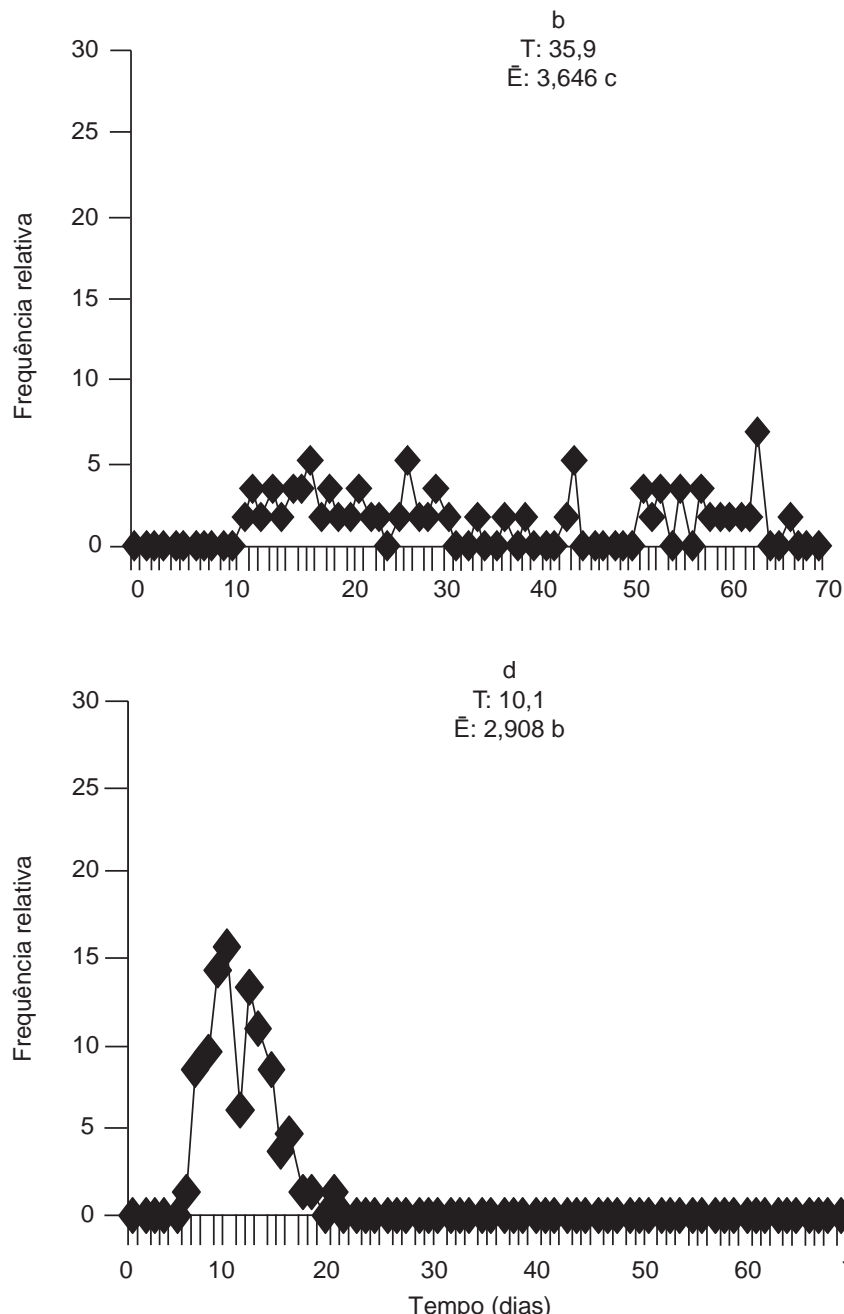

Figura 3. Polígonos de freqüência relativa da germinação de sementes de T. mutabilis em diferentes estádios de maturação (dias pós-antese). a) 14 dias sementes secas; b) 21 dias sementes frescas; c) 21 dias sementes secas; e d) 28 dias com a sementes frescas e secas testadas sob luz branca contínua: $\mathrm{T}$ - tempo médio e $\overline{\mathrm{E}}$ - índice de sincronização da germinação. Letras distintas acompanhado de $\overline{\mathrm{E}}$ indicam diferença significativa entre si $\mathrm{p}<0,05$ de acordo com o teste de Tukey.

Figure 3. Relative frequency of T. mutabilis seed germination under different stages of maturation (days after anthesis). a) 14 days dry seeds; b) 21 days fresh seeds; c) 21 days dry seeds; and d) 28 days dry and fresh seeds evaluated under continuous white light: $\mathrm{T}$ - mean time and $\overline{\mathrm{E}}$ - Synchronization index of germination. Distinct words right of $\overline{\mathrm{E}}$ indicates significantive difference among treatment $\mathrm{p}<0.05$ according to Tukey test. 
unidades vizinhas (Lee 1990). Sugere-se que os frutos e as sementes desenvolvidos primeiramente possuem maior disponibilidade de recursos acelerando o seu desenvolvimento. Nos frutos que se desenvolvem tardiamente, os recursos podem não ser encontrados suficientemente para completar o desenvolvimento, ocorrendo então o aborto das sementes, assim como a senescência antecipada do fruto.

A semente das angiospermas, durante o seu desenvolvimento, passa por três fases distintas: histodiferenciação ou morfogênese inicial; expansão celular e acúmulo de reserva; e a fase final, o dessecamento, em sementes ortodoxas (Cardoso 2004). Em T. mutabilis esta sequiência de fases de desenvolvimento foi observada em um período de 28 dias pós-antese. O tempo entre a abertura da flor e o início da dispersão foi de 40 dias. Este período pode estar relacionado às características ambientais a que as plantas estavam submetidas (ambiente urbano) e também em decorrência da escassez de chuva e altas temperaturas durante o período de marcação e coleta dos frutos.

Aos 28 dias, aparentemente, as sementes já apresentavam baixo conteúdo de água, caracterizado pela abertura das cápsulas e dispersão das sementes, comprovado nos teste de germinação (Figura 1), onde a velocidade e a porcentagem de germinação foi maior neste estádio e no estádio de 21 dias-semente seca, indicando que nas fases finais de maturação desta espécie ocorre uma perda acentuada de água.

Este padrão de dessecamento das sementes também foi observado em Cedrela fissilis (Corvello et al. 1999), Bixa orellana (Amaral et al. 1999), Sesamum indicum (Day 2000), Miconia cinnamomifolia (Pereira \& Mantovani 2001) e Tibouchina granulosa (Lopes et al. 2005), que nas fases iniciais de desenvolvimento, apresentavam frutos e sementes com alto conteúdo de água, em torno de $85 \%$, que tenderam a diminuir nas fases finais do desenvolvimento.

Em Bixa orellana (Amaral et al. 1999) foi observado que após o período em que as sementes atingiram o máximo de peso seco, e com a diminuição acentuada de umidade $(10,4 \%$ na fase final) a germinação também diminuiu. A germinação foi baixa nas fases finais de maturação porque o tégmen da maioria das sementes já estava completamente impermeável, impedindo a entrada de água nas sementes, indicando a presença de dormência física das sementes.

A dormência das sementes é um fenômeno que se instala no decorrer da maturação, sendo uma estratégia das plantas para evitar a germinação na própria planta antes que ocorra a dispersão das mesmas (Nakagawa et al. 2005). Lopes et al. (2005) observaram que as sementes de Tibouchina granulosa tornam-se dormentes, apresentando baixa porcentagem de germinação ao atingirem a maturidade fisiológica.

Em T. mutabilis, no estádio de 14 dias, a germinação não ocorreu em sementes frescas, provavelmente em função do alto conteúdo de água presente nas sementes, pois, quando secas, apresentaram 14\% de germinação. Aos 21 dias, as sementes frescas apresentaram mais de $50 \%$ de germinação, e quando secas $87 \%$, confirmando a hipótese de que o alto conteúdo de água restringe a germinação de sementes em desenvolvimento.

Outra hipótese é que o desenvolvimento das sementes pode continuar ocorrendo durante o lento processo de secagem, em condições ambientais, quando as sementes são mantidas dentro do fruto (Setubal et al. 1996). Em Mucuna aterrima, a secagem no interior da vagem promoveu o desenvolvimento de sementes imaturas, indicando que há translocação de compostos das vagens para as sementes (Nakagawa et al. 2005).

Em sementes ortodoxas, o desenvolvimento só se completa quando as sementes apresentam baixos teores de umidade (Amaral et al. 1999). Possivelmente, o dessecamento tem papel fundamental na interrupção dos processos de desenvolvimento essenciais para a germinação, pois a reidratação de sementes quiescentes conduz à germinação (Bewley \& Black 1994). Em sementes fotossensíveis, a fotoconversão do fitocromo só ocorre em tecidos com pelo menos 15\% de umidade (Takaki et al. 1981). Assim, o grau de umidade dos tecidos é importante para seu processo germinativo.

Sugere-se que quando as sementes da espécie estudada atingem a maturidade fisiológica (em torno de 21 dias) os frutos e sementes sofrem uma perda acentuada de umidade. Este fato foi relatado por muitos autores em trabalhos com maturação, entre eles Corvello et al. (1999), Amaral et al. (1999), Day (2000), Pereira \& Mantovani (2001), Lopes et al. (2005), Nakagawa et al. (2005) para várias espécies. Infelizmente devido ao tamanho reduzido das sementes foi impossível o acompanhamento dessa perda de água ao longo do desenvolvimento e maturação das sementes de T. mutabilis.

A perda progressiva de água durante o processo de desenvolvimento e maturação de sementes influencia diretamente a velocidade de germinação (Lopes et al. 2005, Amaral et al. 1999, Day 2000, entre outros) sendo considerada um bom indicador de maturidade fisiológica das sementes (Amaral et al. 1999, Day 2000). A tendência de aumento contínuo na velocidade de germinação ao longo dos estádios de maturação observada para T. mutabilis também foi observada em Bixa orellana (Amaral et al. 1999) e Tibouchina granulosa (Lopes et al. 2005).

Na espécie estudada, o estádio de 21 dias coincide com a mudança de coloração (verde amarelo claro) no ápice e no pecíolo das cápsulas sendo um indicativo de maturação fisiológica para a espécie podendo então ser colhidos os frutos. Após a secagem das sementes no interior do fruto sob condição ambiente, estas estarão aptas a germinar. A mudança de coloração também é um bom indicativo de maturidade fisiológica como relatado nos trabalhos de Corvello et al. (1999), Lopes et al. (2005) e Nakagawa et al. (2005) para algumas espécies.

Em T. mutabilis o período reprodutivo, da abertura da flor à dispersão das sementes, considerando as flores marcadas, foi concluído em menos de dois meses. Em Tibouchina granulosa, este período foi de três meses e meio, entre os meses de março e julho coincidindo com o inverno (Lopes et al. 2005), enquanto que em T. mutabilis o estudo foi realizado durante a primavera.

As sementes T. mutabilis germinaram somente na luz em todos os estádios avaliados. Além do requerimento da luz para a germinação, as sementes não apresentaram nenhum outro tipo de dormência na fase final de maturação, com as sementes apresentando alta porcentagem de germinação. Lopes et al. (2005) citaram, mas não especificaram a dormência das sementes de $T$. granulosa nas fases finais de maturação, que resultou em baixa porcentagem de germinação.

Os resultados nos permitem concluir que as sementes de Tibouchina mutabilis necessitam de luz para germinar em todos os estádios. Além do requerimento de luz para germinação, as sementes não apresentaram nenhum outro tipo de dormência ao atingir a maturidade fisiológica. A coleta das sementes pode ser feita com bons resultados, na região de Rio Claro-SP, de agosto a novembro, a partir dos 21 dias pós-antese desde que as sementes sejam mantidas dentro do fruto durante a secagem e no início da abertura natural das cápsulas. A mudança na coloração (verde amarelado claro) do ápice e do pecíolo das cápsulas e a abertura natural das mesmas podem ser utilizadas como indicador de maturação fisiológica para sementes de T. mutabilis.

\section{Agradecimentos}

Ao CNPq, pelas bolsas: de mestrado (Edson Simão), de doutorado (Adriana Tiemi Nakamura) e de produtividade em pesquisa (Massanori Takaki). 


\section{Referências Bibliográficas}

AKHALKATSI, M. \& LÖSCH, R. 2005. Water limitation effect on seed development and germination in Trigonella coerulea (Fabaceae). Flora 200(6):493-501.

AMARAL, L.I.V., PEREIRA, M.F.D.A. \& CORTELAZZO, A.L. 1999. Germinação de sementes em desenvolvimento de Bixa orellana. Rev. Bras. Fisiol. Veg. 12(3):273-285.

AMARAL-BAROLI, A. \& TAKAKI, M. 2001. Phytochrome controls achene germination in Bidens pilosa L. (Asteraceae) by very low fluence response. Braz. Arch. Biol. Technol. 44(2):121-124.

BACKES, P. \& IRGANG, B. 2004. Mata Atlântica. As árvores e a paisagem. Editora Paisagem do Sul, Porto Alegre.

BARROSO, G. M., MORIM, M. P., PEIXOTO A. L. \& ICHASO, C. L. F. 1999. Frutos e sementes: morfologia aplicada à sistemática de dicotiledôneas. UFV, Viçosa, p.235.

BEWLEY, J.D. \& BLACK, M. 1994. Seeds: physiology of development and germination. Plenum Press, New York.

CARDOSO, V.J.M. 2004. Germinação. In. KERBAUY, G.B. (Ed). Fisiologia vegetal. Editora Guanabara Koogan, Rio de Janeiro, p.386-408.

CARVALHO, N.M. \& NAKAGAWA, J. 1980. Sementes. Ciência, tecnologia e produção. Fundação Cargill, Campinas.

CORVELLO, W.B.V., VILLELA, F.A., NEDEL, J.L. \& PESKE, S.T. 1999. Maturação fisiológica de sementes de cedro (Cedrela fissilis Vell.). Rev. Bras. Sem. 21(2):23-27.

DAY, J.S. 2000. Development and maturation of sesame seeds and capsules. Field Crops Res. 67(1):1-9.

FEDER, N. \& O'BRIEN, T. P. 1968. Plant microthecnique: some principles and new methods. Amer. J. Bot. 55(1):123-142.

JOHANSEN, D.A. 1940. Plant microtechnique. McGraw-Hill Book, New York.

LABOURIAU, L.G. \& AGUDO, M. 1987. On the physiology of seed germination in Salvia hispanica L. I. Temperature effects. An. Acad. Brasil. Ciênc. 59(1):37-56.

LEE, T.D. 1990. Patterns of fruit and seed production. In: LOVETT DOUST, J. \& LOVETT DOUST, L.(eds). Plant reproductive ecology - Patterns and strategies. Oxford Univ. Press, Oxford, p.179-209.

LOPES, J.C., DIAS, P.C. \& PEREIRA, M.D. 2005. Maturação fisiológica de sementes de quaresmeira. Pesq. Agropec. Bras. 40(8):811-816.

LORENZI, H. 1992. Árvores brasileiras: manual de identificação e cultivo de plantas arbóreas nativas do Brasil. Plantarum, São Paulo.
NAKAGAWA, J., CAVARIANI, C. \& ZUCARELI, C. 2005. Maturação, formas de secagem e qualidade fisiológica de sementes de mucuna-preta. Rev. Bras. Sem. 27(1):45-53

PEREIRA, T.S. \& MANTOVANI, W. 2001. Maturação e dispersão de Miconia cinnamomifolia (DC.) Naud. na Reserva Biológica de Poço das Antas, município de Silva Jardim RJ, Brasil. Acta Bot. Bras. 15(3):335-348.

POPINIGIS, F. 1985. Fisiologia da semente. AGIPLAN, Brasília.

SETUBAL, J.W., ZANIN, A.C.W. \& NAKAGAWA, J. 1996. Efeitos da idade dos frutos, métodos e condição de secagem sobre a qualidade de sementes de quiabeiro (Abelmoschus esculentus (L.) Moench) CV. SANTA CRUZ47. Rev. Bras. Sem. 18(1):138-142.

SOKAL, R.R. \& ROHLF, F. J. 1981. Biometry. W.H. Freeman, New York.

TABARELLI, M. \& MANTOVANI, W. 1999. A riqueza da floresta Atlântica de encosta no estado de São Paulo (Brasil). Rev. Bras. Bot. 22(1):217223.

TAKAKI, M., KENDRIK, R.E. \& DIETRICH, S.M.C. 1981. Interaction of light and temperature on germination of Rumex obtusifolius L., Planta 152(1):209-214.

ZAIA, J.E. \& TAKAKI, M. 1998. Estudo da germinação de sementes de espécies arbóreas pioneiras: Tibouchina pulchra Cogn. e Tibouchina granulosa Cogn. (Melastomataceae). Acta Bot. Bras. 12(3):221-229.

Título: Época de colheita e capacidade germinativa de sementes de Tibouchina mutabilis (Vell.) Cogn.

(Melastomataceae).

Autores: Simão E, Nakamura, AT e Takaki, M

Biota Neotropica, Vol.7 (número 1): 2007

http://www.biotaneotropica.org.br/v7n1/pt/abstract?article+ bn01507012007

Recebido em 01/09/06 - Versão reformulada recebida em 27/11/06 - Publicado em 31/01/2007

ISSN 1676-0603 